\title{
Effect of iontophoresis on fluoride
} uptake in enamel with artificial caries lesion. Braz Oral Res. 2018;33:e037.

\author{
Author's name \\ Where is read: Cintia Pereira MACHADO \\ It should read: Cintia Pereira Machado TABCHOURY \\ Legend \\ Where is read: Pauli MC, Machado CP, Silva SAM, Ambrosano GMB, \\ Lopez RFV, Leonardi GR \\ It should read: Pauli MC, Tabchoury CPM, Silva SAM, Ambrosano GMB, \\ Lopez RFV, Leonardi GR
}

http://dx.doi.org/10.1590/1807-3107bor-2019.vol33.0037erratum 